Maria Cristina Gonzaga ${ }^{2}$

Roberto Funes Abrahão ${ }^{3}$

Oscar Antonio Braunbeck ${ }^{3}$

\section{O uso das luvas de proteção no corte manual da cana-de-açúcar ${ }^{1}$}

\section{Protective gloves for manual harvesting of sugar cane}

\begin{abstract}
Resumo
Uma negociação tripartite entre a Fundacentro, o Sindicato dos Empregados Rurais de Araraquara e a Usina Santa Cruz permitiu a realização do estudo sobre o uso dos equipamentos de proteção individual (EPI) e das ferramentas de trabalho durante a execução da atividade de cortar manualmente a cana-de-açúcar.

A problemática se manifestou frente às estratégias utilizadas pelos trabalhadores para viabilizar o uso conjunto das ferramentas e dos EPI, prescritos como obrigatórios pela Norma Regulamentadora Rural no 4 (Ministério do Trabalho e Emprego) e pelas normas internas da empresa. A principal estratégia desenvolvida pelos trabalhadores foi emborrachar o cabo do facão com o objetivo de minimizar o efeito da falta de aderência entre a luva de proteção e o cabo da ferramenta.

A metodologia utilizada no presente estudo foi analisar qualitativamente, através da aplicação de questionários, quatro modelos de luvas junto a 47 trabalhadores, além de analisar quantitativamente o coeficiente médio de atrito estático $(\mu)$ desenvolvido entre as luvas e a madeira com que é confeccionado o cabo do facão. Os experimentos foram feitos com madeira limpa e emborrachada e com luvas novas e usadas.

A pesquisa qualitativa apontou a luva de proteção de raspa de couro e nylon como a preferida dos trabalhadores, pelo conforto advindo do fato desta luva se ajustar bem às mãos, de não prejudicar os movimentos e não ocasionar danos às mãos.

O coeficiente de atrito estático ( $\mu$ e) depende do tipo de luva, da condição da luva e do tipo de superfície.
\end{abstract}

Palavras-chave: luva de proteção, atrito estático, cana-de-açúcar.

\begin{abstract}
This study on the personal protective equipment (PPE) and the tools used for the manual harvesting of sugar cane resulted from a tripartite negotiation between FUNDACENTRO, the Rural Workers Union in Araraquara, and the Santa Cruz sugar mill.

The subject came out while workers were trying to adapt themselves to the set of tools and PPE (Personal Protective Equipment) demanded not only by the Regulating Standard Rural $n^{\circ} 4$ set by the Ministry of Labor and Employment, but also to their companies internal rules. One of their strategies to improve their gloves adherence to the handles of their knives was covering them with rubber.

Four models of gloves were analyzed not only from the point of view of their quality, through questionnaires distributed to 47 workers, but also their quantity, through the average static friction coefficient $(\mu)$ produced by the gloves when holding the wooden knife handles. Clean wood and wood covered with rubber, new and used gloves were tested.

The qualitative research showed that workers prefer gloves made of leather and nylon scrapings because they fit their hands comfortably, without causing aches or blocking their movements.

The static friction coefficient ( $\mu$ e) is determined by the glove material, its condition and the kind of surface.
\end{abstract}

Keywords: protective gloves, static friction, sugar cane. 


\section{Introdução}

O uso dos EPI é uma exigência legal da Norma Regulamentadora Rural no 4 do Ministério do Trabalho - NRR 4 (Ministério do Trabalho e Emprego, 2003). Consta no item 4.1 a definição do EPI como todo dispositivo de uso individual destinado a preservar e proteger a integridade física do trabalhador. O item 4.2 estabelece que o EPI deve ser adequado ao risco. $\mathrm{O}$ item 4.3 estabelece que as peculiaridades da atividade devem ser respeitadas no fornecimento da proteção para os membros superiores, contemplando as atividades em que haja riscos ocasionados por materiais escoriantes, abrasivos, cortantes e perfurantes. A atividade dos cortadores de cana se insere neste caso, pois, na sua execução, é necessário o uso do facão. No seu item 4.6, a norma estabelece que compete ao trabalhador usar obrigatoriamente os EPI indicados para a finalidade a que se destinarem.

A Associação Brasileira de Normas Técnicas (ABNT, 1996) define e aprova as normas para a fabricação dos EPI. O Instituto de Pesquisa Tecnológica (IPT) é o instituto que executa os ensaios exigidos pelas normas da ABNT. Os resultados são encaminhados para o Ministério do Trabalho e Emprego para ser emitido o certificado de aprovação (CA). O artigo 167 da Consolidação das Leis do Trabalho estabelece que os EPI só podem ser postos à venda com a indicação do CA.

A NBR 13712 é a norma que deve ser cumprida para a fabricação das luvas de

\section{Objetivo}

Avaliar o uso das luvas de proteção na atividade do corte manual da cana-de-

\section{Objetivos Específicos}

Verificar, junto aos trabalhadores, os problemas relacionados ao uso das luvas de proteção junto ao facão na atividade do corte manual da cana-de-açúcar.

\section{Metodologia}

Durante duas safras, foram acompanhados dois grupos de trabalhadores, junto aos quais foram aplicadas entrevistas semi-estruturadas e observações em campo.

Na safra de 2001, o grupo era formado por 35 trabalhadores; durante a safra de 2002, o grupo era formada por 47 trabalhadores. proteção em couro ou tecidos para proteção contra riscos mecânicos. A EN 388 é a norma utilizada para as luvas em couro e nylon contra riscos mecânicos. Entre eles estão os riscos contra materiais cortantes. Portanto, estas são as normas que definem os pré-requisitos para as luvas que devem ser utilizadas pelos cortadores de cana-de-açúcar.

Os atributos de conforto e adequação às peculiaridades da atividade estão previstos na NRR 4. Entretanto, os cortadores de cana sentem desconforto e insegurança no uso das luvas, já que normalmente o cabo do facão não é aderente à luva de proteção em raspa de couro (Dias, Neto \& Santos , 1989; Gonzaga, 2002, 2004). Talvez isso seja reflexo das normas de fabricação de luvas de proteção.

O uso das luvas de proteção na atividade do corte manual da cana-de-açúcar é de extrema importância, já que a mão é a parte do corpo atingida nesta atividade e o facão é o principal agente causador de acidentes, segundo Reina, Goldim \& Ludemir (1993), Meirelles et al. (1983), Gonzaga (1996) e Bomfim (2001).

Busca-se, com este trabalho, avaliar, sob uma perspectiva ergonômica, o impacto da utilização dos EPI durante a execução do corte manual da cana-de-açúcar, propondo melhorias especificamente relacionadas às luvas de proteção e ao cabo do facão, considerando a atividade exercida e os usuários.

açúcar sob o ponto de vista da segurança e do conforto.

Determinar o coeficiente de atrito através de ensaios experimentais com quatro tipos de luvas de proteção e a madeira utilizada na confecção dos cabos dos facões.

As improvisações dos trabalhadores, observadas no ano de 2001, direcionaram as ações desenvolvidas no ano de 2002, ou seja, foram feitos ensaios experimentais para quantificar o coeficiente de atrito estático junto ao material de quatro luvas de proteção novas e usadas: raspa de couro/metal (CA = 11.862), kevlar (CA = 12,503), algodão/ 
borracha ( $\mathrm{CA}=4.250)$ e raspa de couro/ nylon $(\mathrm{CA}=11.862$, segundo informações do setor de segurança da empresa analisada), e a madeira com a qual é confeccionado o cabo do facão (sem borracha e emborrachado).

Os trabalhadores usaram as luvas avaliadas nos ensaios experimentais com objetivo de obter informações qualitativas

\section{Resultados e Discussão}

O grupo avaliado no ano de 2001 era composto de 35 trabalhadores (54,55\% do sexo feminino e $45,45 \%$ do sexo masculino); neste período foi feito o diagnóstico preliminar sobre o uso dos EPI.

O grupo avaliado no ano de 2002 era composto por 47 trabalhadores $(59,57 \%$ do sexo feminino e $40,42 \%$ do sexo masculino); neste período foi feito o estudo sobre as luvas de proteção. relacionadas às luvas; foram entregues 3 pares de luvas para cada trabalhador.

Para a análise dos dados qualitativos e quantitativos foram utilizados os softwares EPIINFO (1994) e SAS (2001). O modelo estatístico aplicado será a Análise de Variância (ANOVA). O atrito foi a variável dependente, enquanto o tipo de luva, sua condição e o tipo de revestimento da madeira foram as variáveis independentes.

Tabela 1 Aceitação do uso dos equipamentos de proteção individual

\begin{tabular}{ccc}
\hline EPI & Protege* $^{*}$ & Atrapalha* \\
\hline Perneira de proteção & $87,5 \%$ & $45,2 \%$ \\
Óculos de proteção & $87,0 \%$ & $50,0 \%$ \\
Luvas de segurança & $64,5 \%$ & $79,4 \%$ \\
Sapato de proteção & $77,5 \%$ & $45,2 \%$ \\
\hline
\end{tabular}

Fonte: GONZAGA (2002)

*Respostas múltiplas

No questionamento feito aos trabalhadores sobre a perneira de proteção, 45,2\% admitiram que a mesma atrapalha (Tabela 1 ). Os motivos apontados pelos trabalhadores foram os seguintes:

- a perneira esquenta, escorrega e machuca as pernas durante a execução da atividade;

- no corte da cana-de-açúcar em curva de nível, a declividade do terreno exige uma postura que interfere no ângulo entre o pé e a perna, o que dificulta a curvatura dos pés. Como o material com que é confeccionada a perneira é duro, a região do metatarso sofre ferimentos;

- ela tem na sua parte lateral superior um encaixe rígido para guardar o suporte de lima (ferramenta utilizada para manter o fio do facão). Segundo os trabalhadores, isso facilita a perda da lima e pode causar ferimentos no joelho.

No questionamento feito aos trabalhadores sobre os óculos de proteção, 50\% dos trabalhadores afirmaram que o mesmo atrapalha (Tabela 1). Os motivos alegados pelos trabalhadores foram os seguintes:

- depois de horas de uso, houve queixas de tontura e dor de cabeça;

- os óculos apertam muito o rosto e muitas vezes ocasionam ferimentos;

- no corte da cana crua, as folhas entram por baixo dos óculos e a fuligem e o joçá penetram nos olhos, provocando irritações.

$\mathrm{Na}$ indagação com relação à botina de segurança, os dados indicaram que para $45,2 \%$ dos trabalhadores elas atrapalham (Tabela 1). A principal queixa apontada por eles é a dificuldade de manutenção adequada do equipamento pelo fato de a empresa fornecer apenas um par. Isso ocorre principalmente quando a atividade é desenvolvida durante a chuva, situação em que o sapato naturalmente fica molhado e endurece, conseqüentemente aperta e machuca os pés. O envelhecimento precoce das botinas foi citado como um fator que gera problemas, sempre relacionados ao endurecimento. 
No questionamento junto aos trabalhadores sobre se a luva de proteção atrapalhava a execução do trabalho, obteve-se a seguinte resposta: 79,4\% admitiram que sim (Tabela 1). Os motivos expostos pelos trabalhadores para justificar a resposta acima foram os seguintes:

- na execução do corte manual da canade-açúcar, é necessário usar o facão em contato com as luvas de raspa de couro, porém os trabalhadores afirmam que o cabo do facão não é aderente à luva e o uso desse conjunto gera uma situação insegura, facilitando a ocorrência de acidentes;
- a luva endurece em contato com a sacarose e as cinzas presentes na cana-deaçúcar, causando calos, bolhas e rachaduras nas mãos dos cortadores;

- o tamanho das luvas é inadequado ao tamanho das mãos dos trabalhadores (Figura 1), já que as mesmas têm tamanho único; muitas vezes, a luva pressiona as unhas, que ficam roxas, podendo até cair;

- dormência nas mãos e dores nos braços e nas costas podem ocorrer, pois, segundo a fala de um trabalhador: "é necessário fazer muita força para conseguir segurar o facão junto às luvas”.

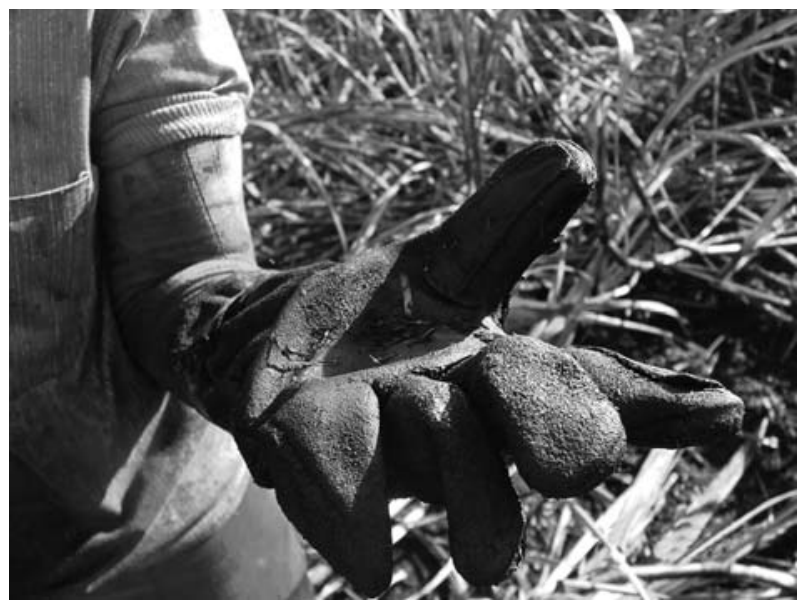

Figura 1 Cortadora usando luva de tamanho inadequado

A luva de proteção foi apontada como sendo o EPI que mais atrapalha (Tabela 1). Em função disso, selecionou-se a luva para ser avaliada após a fase do diagnóstico preliminar.

O uso da luva de proteção exige dos trabalhadores o desenvolvimento das seguintes estratégias: emborrachar o cabo do facão $82,7 \%$; usar luva de pano sobre a de raspa 6,9\%; molhar as luvas de raspa - 6,9\%; e não usar luva na mão que segura o facão - 3,4\%.
A problemática relacionada às luvas de proteção no corte manual da cana-de-açúcar é abordada por Dias, Neto \& Santos (1989) e por Gonzaga (2002): a luva de proteção causa ferimentos, pois, durante o processo, a cana é queimada, depositando cinzas; estas cinzas, em contato com a sacarose e a água, formam uma mistura que, em contato com as luvas de raspa, penetram na pele das mãos. Esse processo bioquímico produz descamações, fissuras e dermatites nas mãos, como mostra a Figura 2.

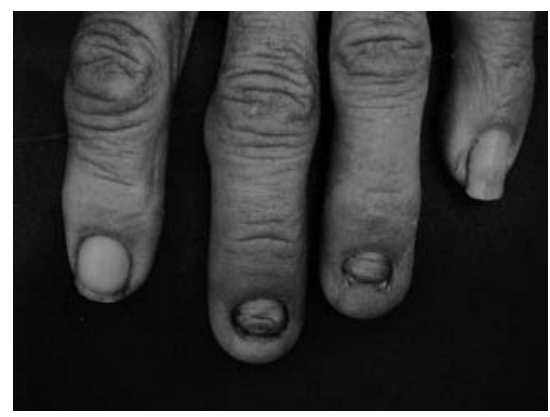

Figura 2 Mão de uma trabalhadora com as unhas lesionadas 
Com relação ao tamanho das luvas de proteção (Figura 1), o tamanho único, que desconsidera a variabilidade dos usuários, é um problema principalmente para as mulheres, que normalmente têm as mãos menores que os homens: em função disso, elas diminuem $2 \mathrm{~cm}$ no cabo do facão para conseguir segurar o mesmo com firmeza.

Segundo a Organização das Nações Unidas para Agricultura e Alimentação - FAO (1992) -, quando se tenta adequar as ferramentas ao trabalhador, é preciso levar em conta a enorme variação de tamanho do corpo, entre as raças entre o homem e a mulher e até mesmo entre indivíduos do mesmo sexo e raça.

Com relação ao material de confecção, a raspa de couro com que é confeccionada a luva de proteção endurece em contato com a sacarose, dificultando o movimento de mãos e braços.

Com relação ao formato, a localização das costuras internas da luva coincidindo com a pega do cabo do facão machuca as mãos.

Segundo Ali (2001), grande número de dermatoses alérgicas em trabalhadores tem sido produzido por equipamentos de proteção individual. Algumas categorias são mais atingidas em virtude do uso de EPI em circunstâncias especiais.

Armstrong (1985, 2003) descreve que o nível de fricção entre os elementos cabo e luva interfere de forma significativa na carga da pega nas mãos. Esse fato foi confirmado por McGorry (2001), que apresenta alguns fatores que interferem na interação cabo/mão e na força de preensão: diâmetro, comprimento, forma, textura da superfície, luvas, contaminantes, vibração etc.

Freivalds \& Tsaousidis (1997) observaram o problema da interferência do retorno tátil com relação ao uso de luvas de proteção, quando a mão tem que manusear um objeto que não tenha fricção junto ao material da luva. As estratégias desenvolvidas pelos cortadores buscam justamente aumentar o índice de fricção entre a luva e o cabo do facão.

Com relação aos coeficientes de atrito, temos alguns resultados que comprovam o seguinte:

1. o coeficiente de atrito estático depende do material com que é confeccionada a luva de proteção: algodão/borracha $(\mu \mathrm{e}=1,24)$, $\operatorname{kevlar}(\mu \mathrm{e}=1,27), \mathrm{raspa} / \mathrm{metal}(\mu \mathrm{e}=0,92) \mathrm{e}$ raspa/nylon ( $\mu \mathrm{e}=0,98)$;

2. o coeficiente de atrito estático depende do estado da luva: luvas novas $(\mu \mathrm{e}=1,14) \mathrm{e}$ luvas usadas $(\mu \mathrm{e}=1,06)$;

3. o coeficiente de atrito estático depende do tipo de superfície: madeira limpa $(\mu \mathrm{e}=$ $0,85)$ e madeira emborrachada $(\mu \mathrm{e}=1,36)$.

Com o decréscimo no coeficiente de atrito, ocorreu o aumento da força de preensão aplicada de $158 \%$ para os materiais úmidos e de $326 \%$ para o mesmo material seco (Buchholz et al., 1988, 324).

A Tabela 2 apresenta um resumo das respostas obtidas quando se avaliou a seguinte questão: "qual é a melhor luva de proteção?”

Tabela 2 Resultados relativos à seguinte questão: qual é a melhor luva de proteção?

\begin{tabular}{ll}
\hline \multicolumn{1}{c}{ Tipo de Luva } & A melhor \\
\hline Algodão/borracha $(\mathrm{n}=36)$ & $76,47 \%$ \\
Kevlar $(\mathrm{n}=38)$ & $51,43 \%$ \\
Raspa de couro/metal $(\mathrm{n}=46)$ & $10,87 \%$ \\
Raspa de couro/nylon $(\mathrm{n}=33)$ & $90,32 \%$ \\
\hline
\end{tabular}

$\mathrm{N}=$ número de trabalhadores

Os dados apresentados na Tabela 2 não contemplaram os 47 trabalhadores do grupo, pois foi uma rotina no desenvolvimento deste estudo os trabalhadores estarem ausentes, porém a justificativa para essa ausência nunca nos foi dada.

Os motivos que justificam os resultados apresentados na Tabela 2 são os seguintes:

- Luva de algodão e borracha: é macia e aderente ao cabo do facão, ajusta bem à mão e não prejudica os movimentos;
- Luva de kevlar: enrola à palma da mão por ter muita aderência ao cabo do facão, em função disso prejudica os movimentos das mãos;

- Luva de raspa e nylon: ajusta bem na palma da mão e não prejudica os movimentos, porém escorrega no cabo do facão;

- Luva de raspa e metal: escorrega no cabo do facão e não se ajusta à mão, o que dificulta o movimento. 
Freivalds \& Tsaousidis (1997) destacam que as luvas afetam a força exercida, interferindo no desempenho dos trabalhadores e fazendo com que eles aumentem as exigências musculares, gerando problemas osteomusculares.

O fator decisivo para o conforto das luvas não é apenas a aderência advinda do atrito, pois a falta de atrito enseja o desenvolvimento pelos

\section{Referências Bibliográficas}

ALI, S. A. (org.) Dermatoses Ocupacionais. São Paulo: Fundacentro: FUNDUNESP, 1994. 223 p.

ARMSTRONG, T. J. Mechanical considerations of skin in work. American Journal of Industrial Medicine. Nova York, v.8, p. 463472, 1985.

. Upper Limb Musculoskeletal Disorders and Force. Disponível em: < http:// umrerc.engin.umich.edu/jobdatabase/ Background/Force/Force.asp > . Acesso em 25 fev. 2003

ASSOCIAÇÃO BRASILEIRA DE NORMAS TÉCNICAS. NBR 13712: Luvas de Proteção. Rio de Janeiro, 1996.

BOMFIM, A. S. V.; XAVIER, F. A. B.; SAMPAIO, M. do R.; PIVA, R. Canas e bagaços: a organização do trabalho e as repercussóes no quadro de saúde e segurança do cortador de cana do Recôncavo Bahiano. Salvador: Fundacentro, 2001. 54 p.

BRASIL. Ministério do Trabalho e Emprego. Norma Regulamentadora Rural no4. Disponível em <http://www.mte.gov.br> Acesso em 18 jan. 2003.

BUCHHOLZ, B.; FREDERICK, L. J.; ARMSTRONG, T. J. An investigations of human palmar skin friction and the effects of materials, pinch force and moisture. ERGONOMICS. London, v. 31, n. 3, p. 317-325, 1988.

DIAS, J. L. A.; NETO, M. F.; SANTOS, N. Concepção ergonômica de máquinas e equipamentos na metodologia de projeto de produtos. In: Anais do I Encontro panamericano de ergonomia - X Congresso Brasileiro de Ergonomia. Rio de Janeiro: ABERGO, 2000. p. 34-42.

EN 388. Luvas de Proteção Contra Riscos Mecânicos, 1994. Disponível em <http:// idec.gr/ppe/pt/en388_pt.htm > Acesso em 24 março 2003.

EPI INFO, Versão 6. Um programa de processamento de texto, banco de dados e trabalhadores da estratégia "emborrachamento" do cabo de facão. Segundo os trabalhadores, outros fatores que não são passíveis de improvisação devem ser considerados, como, por exemplo, o dimensionamento das costuras internas das luvas, a maciez do material com que as mesmas são fabricadas e o tamanho, embora, para minimizar o efeito do tamanho inadequado, as trabalhadoras sobrepõem luvas para ajustá-las.

estatística para Saúde Pública em microcomputadores IBM compatíveis. [Computer Program]. Produzido por The Division of Surveillance and Epidemiology, Epidemiology Program Office, Centers of Disease Control and Prevention. Atlanta, EPI Info, 1994.

GONZAGA, M. C. O uso dos equipamentos individuais de proteção e das ferramentas de trabalho no corte manual da cana-de-açúcar. São Paulo: Fundacentro, 2002. 39p.

GONZAGA, M. C.; BUSSACOS M. A.; SILVA, M. A.; FERREIRA, L. L. Estudo das comunicações de acidentes de trabalho na região de Catanduva. São Paulo: Fundacentro, 1996. $58 \mathrm{p}$.

MCGORRY, R. W. A system for the measurement of grip forces and applied moments during hand tool use. Applied Ergonomics. Londres, v.32, p.271-279, 2001. Disponível em <www.elsevier.com/locate/ apergo $>$ Acesso em 18 nov. 2002.

MEIRELLES, C. E; YASMASHITA, R. Y. Segurança do trabalho - um pequeno panorama dos acidentes de trabalho na área rural. In: Anais do XVII Congresso Brasileiro de Engenharia Agrícola. Sorocaba: CENEA/ MA, v. 2, p. 709-723, 1988.

ORGANIZAÇÃO DAS NAÇÕES UNIDAS PARA AGRICULTURA E ALIMENTAÇÃO FAO. Introdução à ergonomia aplicada às atividades florestais em países em desenvolvimento. Roma, 1992. 173 p.

REINA, L.; GONDIM, M. L.; LUDEMIR, A. M. Os trabalhadores invisíveis, condição de vida e trabalho das crianças e adolescentes. Relatório de Pesquisa. Recife. Centro Josué de Castro de Estudos e Pesquisas. 1993. 58 p.

TSAOUSIDIS, N.; FREIVALDS, A. Effects of gloves on maximum force and the rate of force development in wrist flexion and grip. In: TWENTY-FIRST ANNUAL AMERICAN SOCIETY OF BIOMECHANICS. Califórnia: Clemson University, 1997. p. 24-27. 